\title{
Desigualdades e pandemia de COVID-19: contribuições para o debate sobre as particularidades socio-históricas, educacionais e das juventudes do Brasil
}

\author{
Inequalities and the COVID-19 pandemic: contributions to the debate about \\ Brazilian youths' social-historical and educational particularities
}

(D) Francisca Rejane Bezerra Andrade

Pós-doutora em Ciências da Educação

Universidade Estadual do Ceará - UECE.

Fortaleza, Ceará - Brasil.

rejane.bezerra@uece.br

Resumo: O presente artigo objetiva contribuir para as reflexões críticas em torno dos processos educacionais desenvolvidos no Brasil. Para tanto, realizam-se análises que caminham para o entendimento de que o sistema educacional brasileiro legitima a seletividade e o fracasso dos alunos por meio de um sistema de avaliação meritocrático e excludente próprio da sociedade capitalista. Tenciona-se, ainda, favorecer a compreensão das relações entre os problemas estruturais como a pobreza, o racismo e a segmentação do mercado de trabalho e a ampliação das disparidades educacionais no país, articulando-as aos impactos da pandemia de Covid-19 para a escolarização da população brasileira. Para finalizar, direciona-se o olhar sobre as juventudes brasileiras, com o intuito de compreender os impactos do quadro pandêmico atual para a vida escolar e profissional deste segmento populacional.

Palavras chave: desigualdades; educação; pandemia de COVID-19; juventudes.

Abstract: This paper has the goal to contribute to critical reflections around the educational processes developed in Brazil. Therefore, this research conducts analysis that lead to the understanding that the brazilian educational system legitimates students' selectivity and failure by a meritocratic and excluding evaluation system, which relates to the capitalist society. Furthermore, we propose a favoring to the comprehension of the relations between structural problems involving poverty, racism, and job market segmentation and the country's educational disparity increase, making an articulation with the Covid-19 pandemic impacts to the brazilian population's scholarity. Finally, an eye is directed to the brazilian youths, with the intent of understanding the current pandemic context impacts to the scholar and professional paths of this population's segment

Key-words: inequalities; education; Covid-19 pandemic; youths.

Cite como

(ABNT NBR 6023:2018)

ANDRADE, Francisca Rejane Bezerra. Desigualdades e pandemia de COVID-19: contribuições para o debate sobre as particularidades socio-históricas, educacionais e das juventudes do Brasil. Dialogia, São Paulo, n. 39, p. 1-14, e20612, set./dez. 2021. Disponível em: https://doi.org/10.5585/39.2021.20612.

American Psychological Association (APA)

Andrade, F. R. B. (2021, set./dez.) Desigualdades e pandemia de COVID-19: contribuições para o debate sobre as particularidades sociohistóricas, educacionais e das juventudes do Brasil. Dialogia, São Paulo, 39, p. 1-14, e20612. https://doi.org/10.5585/39.2021.20612. 


\section{Introdução}

Apesar de a sociedade brasileira vivenciar avanços nos padrões de desenvolvimento e modernidade ao longo de sua história de mais de cinco séculos, perpetua uma realidade plena de desigualdades e pobreza.

A tradição autoritária e conservadora brasileira reverbera uma patente incivilidade ancorada no imaginário social constituído por uma tradição escravista e patriarcal (TELLES, 2006), o que contribui para que o Brasil vivencie uma experiência republicana em que: "Nos falta, ainda mais, o exercício dos direitos sociais, qual seja, a participação na riqueza coletiva: o direito, ou melhor, o pleno exercício do direito à saúde, educação, ao emprego, à moradia, ao transporte e ao lazer" (SCHWARCZ, 2019, p. 64). Segundo Telles, este cenário favorece que se institua um paradoxo:

[...] Paradoxo de um projeto de modernidade que desfez as regras da República oligárquica, que desencadeou um vigoroso processo de modernização econômica, social e institucional, mas que repôs a incivilidade nas relações sociais. [....]. Trata-se de um peculiar modelo de cidadania, dissociado dos direitos políticos e também de regras da equivalência jurídica, tendo sido definida estritamente nos termos da proteção do Estado, através de direitos sociais como recompensa ao cumprimento com o dever do trabalho [...]. É a cidadania regulada [...]. Dissociado de um código universal de valores políticos e vinculado ao pertencimento corporativo como condição para a existência cívica, é um modelo de cidadania que não construiu a figura moderna do cidadão referida a uma noção de indivíduo como sujeito moral e soberano nas suas prerrogativas políticas na sociedade (TELLES, 2006, p. 89-90).

Nossas particularidades socio-históricas influenciam a constituição de um sistema educacional neoconservador com o objetivo de prover condições necessárias para a competitividade internacional e o lucro e favorecer a reprodução das desigualdades. Para tanto, uma série de políticas e propostas educacionais são implementadas desde a última Lei de Diretrizes e Bases da Educação Nacional de 1996, que pouco têm colaborado para reduzir o histórico e estrutural déficit educacional, ao passe em que as disparidades sociais se reproduzem em nosso país.

A educação, portanto, em sua forma obrigatória gratuita e de "qualidade" vem sendo conquistada de forma expressivamente desigual, considerando a sociedade de classes e o percurso político-cultural do clientelismo, da invisibilidade do povo em primazia às questões e interesses burgueses, salvo os ganhos significativos até aqui.

Em face do exposto, o presente artigo objetiva contribuir para as reflexões críticas em torno dos processos educacionais desenvolvidos no Brasil. Para tanto, ele se estrutura da seguinte forma: após esta introdução, a seção seguinte propõe corroborar para o entendimento de que o sistema educacional brasileiro legitima a seletividade e o fracasso dos alunos através de um sistema de 
avaliação meritocrático e excludente próprio da sociedade capitalista. Logo após, abordar-se-á brevemente as relações entre os problemas estruturais como a pobreza, o racismo e a segmentação do mercado de trabalho brasileiros e a ampliação das disparidades educacionais no país. $\mathrm{Na}$ sequência, analisa-se os impactos da pandemia de Covid-19 para a escolarização da população em idade escolar, direcionando o olhar sobre as juventudes brasileiras através de pesquisa realizada pelo Conselho Nacional da Juventude (CONJUVE) (2021), na busca por compreender os impactos das transformações do mundo globalizado e capitalista para a sociedade brasileira.

\section{O processo de reprodução do sistema capitalista e a sua relação com a educação}

A obra Da relação com o saber às práticas educativas, de autoria de Bernard Charlot (2013), demarca a importância de se compreender a relação entre trabalho e educação, bem como as suas implicações sobre o desenvolvimento humano e social. Em dado momento de sua obra, Charlot ressalta que

\footnotetext{
Não haveria espécie humana sem o trabalho, não há ser humano sem educação, mas ainda não foi construída uma solidariedade consciente, reflexiva e universal entre todos os seres humanos. Nessa situação, quando levantadas as questões do trabalho, da educação e das relações entre ambas, sempre se encontram, ao mesmo tempo, mas sob formas que variam conforme os tempos e os lugares, a questão da humanidade do ser humano e a da exploração de homens por outros homens (CHARLOT, 2013, p. 89).
}

O autor afirma que a configuração de como o trabalho e a educação se relacionam atualmente "continua sendo permeada pela ameaça da dominação, da exploração, da alienação" (2013, p. 86). Sob esta perspectiva, o sistema educacional é essencial ao processo de produção de trabalhadores para o sistema capitalista, visto que contribui para a formação da mão de obra necessária à produção e reprodução do sistema. E a escola, enquanto espaço social, é responsável por ofertar a qualificação do trabalhador como meio de preparação para um trabalho, ao mesmo tempo em que é também espaço de resistência e confronto entre sujeitos sociais.

$\mathrm{Na}$ medida em que as contínuas demandas formativas do sistema capitalista de produção passam a exigir maior recurso educacional na contemporaneidade, visto que ocorre uma permanente desvalorização da força de trabalho, vivencia-se um movimento de transferência dos modelos de racionalidade administrativa para a organização do trabalho na escola, favorecendo a adoção de critérios avaliativos de rendimento escolar através da concorrência entre instituições de ensino e apresentando impactos significativos no trabalho pedagógico.

As exigências formativas recaem, portanto, sobre a formação geral, visto que se busca constituir uma base sólida de conhecimentos aos trabalhadores para que possam se adaptar às 
mudanças do novo sistema capitalista. Essa demanda fortalece a importância da garantia da universalização do ensino fundamental no Brasil, que responderá às exigências de requisitos básicos capazes de qualificar os trabalhadores para a nova dinâmica de trabalho. Maceno (2019) contribui com essa discussão quando afirma que

A educação contribui para diminuir as tensões sociais, formar técnico-profissionalmente e ideológico-politicamente o homem necessário à reprodução do capital na fase histórica em que se encontre, mantendo intactas as diferenças sociais que são a base da desigualdade da educação. Embora a educação seja uma construção social de todo o gênero humano, é privadamente apropriada assim que é instituída a divisão social do trabalho. A educação não atende de modo igualitário ao conjunto dos homens, mas à reprodução social capitalista a serviço de quem atua como elemento importante de sua continuidade, consequentemente, por essa via à classe dominante (MACENO, 2019, p. 64).

E a escola funciona, à vista disso, como uma instituição seletiva, responsável por realizar uma triagem prévia para o mercado de trabalho e, para tanto, coloca-se como instituição legitimadora e com determinado prestígio, mediante a possibilidade de contribuir para a ascensão dos sujeitos sociais através da via educacional.

Essa realidade leva à indagação sobre a organização da escola e sua estrutura de caráter excludente - apesar das resistências cotidianas a esse processo - que tem requerido contínuos processos avaliativos meritocráticos, estimulando a concorrência entre escolas e alunos, e elitizando o acesso à escolarização através da busca por melhores desempenhos.

Construído fora da realidade da escola, esse processo avaliativo - que define padrões de excelência e fracasso sob o princípio liberal da livre concorrência - estigmatiza um número considerável de crianças, adolescentes, jovens e adultos que não têm acesso à determinados saberes e, por conseguinte, passam a ser classificados como incapazes e são responsabilizados por sua exclusão social. É evidente que se trata de uma avaliação meritocrática, que favorece a concorrência desigual entre alunos com histórias de vida e de camadas sociais diferentes. Para Lima, Afonso e Gomes,

[...] Em tal contexto, a escola tende a ser representada como uma agência técnico-racional em busca das soluções mais eficazes e eficientes, inserida em ambiente competitivo, tudo mensurado e hierarquizando, tendendo a substituir o pensamento pedagógico e o conhecimento de educadores profissionais pelas evidências empíricas resultantes do estabelecimento de nexos de causalidade, pelos resultados de avaliações externas, pela disseminação e emulação das chamadas "melhores práticas" (LIMA; AFONSO; GOMES, 2019, p. 167).

Esse movimento desconsidera relevantes fatores que influenciam e até mesmo determinam o êxito ou não do aluno numa avaliação educacional, visto que o compromisso desse sistema de 
avaliação é atender aos objetivos e interesses da lógica capitalista de produção. Na concepção de Charlot (2013).

[...] a lógica neoliberal da concorrência tende a reduzir a educação a uma mercadoria escolar a ser rentabilizada no mercado de empregos e das posições sociais e isso faz com que formas de aprendizagem mecânicas e superficiais, desconectadas do sentido do saber e de uma verdadeira atividade intelectual, tendam a predominar. [...] (CHARLOT, 2013, p. 60-61).

Enfim, subordina-se a educação ao mercado, convertendo-a em mais um instrumento de dualização e polarização social que caracteriza o projeto neoliberal no país, caminhando numa direção contrária aos direitos sociais inscritos na Constituição Brasileira de 1988.

O discurso mercantilizado do acesso à educação foi assumindo uma retórica neoconservadora e antidemocrática no Brasil, favorecendo o desenvolvimento de esquemas de avaliação no sistema educacional brasileiro, onde os que mais têm, mais terão, e os que menos têm, menos terão.

Ao abordar a realidade da escola brasileira e mantendo um relevante diálogo com os argumentos efetuados até o momento, Carrano (2018) pondera que

[...] Estamos hoje diante de uma "batalha cultural" pelos sentidos das relações sociais mais amplas e da vida escolar, em particular. A nossa encruzilhada civilizatória é saber se reaprenderemos o caminho de democratização inconclusa da sociedade brasileira que iniciamos após a ditadura civil-militar. Conseguiremos ter um projeto de país que busque diminuir as desigualdades, combater as injustiças, tecer relações sociais e arcabouços institucionais para consolidarmos uma nação justa, fraterna e solidária ou sucumbiremos diante das forças do conservadorismo mais reacionário, que se aproveitam do clima de insegurança em que nos encontramos para emplacar uma agenda anticidadã, calcada na intolerância com a diferença, na destruição do estado laico, no punitivismo como sucedâneo da justiça democrática e na manutenção dos privilégios e violências múltiplas de classe, raça, gênero e idade? (CARRANO, 2018, p. 67).

O panorama delineado por Carrano contribui para que se compreenda as correlações de forças que instituem o atual momento histórico brasileiro e mundial, somando-se a ele o contexto da pandemia de Covid-19. Diante deste cenário urge a importância de um olhar crítico sobre as desigualdades e a exclusão no Brasil, tal como suas repercussões na escolarização da população, tema que será abordado na sequência.

Desigualdades estruturais e oportunidades educacionais - a construção de uma cidadania incompleta no Brasil

O Brasil adentra na segunda década do século XXI com quase 27 milhões de pessoas vivendo na linha de pobreza extrema (IBGE, 2020), e os efeitos devastadores da pandemia de Covid-19 contribuem para ampliar as fragilidades históricas das estruturas de proteção social brasileiras, que circunscrevem uma indefinição nos rumos das políticas sociais, particularmente 
daquelas destinadas aos grupos sociais mais vulneráveis, revelando que o caminho traçado pelo Brasil não levará à ascensão social almejada, como bem explicitado por León (2016),

\begin{abstract}
Qualquer tentativa de política econômica, social e cultural que almeje promover a ascensão/mobilidade social de forma definitiva e integrativa deve primeiro ir nas raízes dos problemas da sociedade brasileira como nação inconclusa e promover uma verdadeira reordenação das prioridades nacionais. Uma política econômica de ajuste fiscal como a atual onde direitos trabalhistas e sociais inscritos na Carta Magna estão postos em xeque e que os interesses do setor bancário-financeiro são prioridades é um passo na direção oposta à ascensão social sustentada (LEÓN, 2016, p. 16).
\end{abstract}

Apesar de se ter vivenciado um avanço no combate à pobreza no Brasil, não é possível afirmar que ocorreu uma redução das desigualdades socioeconômicas no país, até porque a sociedade brasileira é "alicerçada pelo capitalismo, que traz, em seu bojo, alguns antagonismos tais como: a dominação, a desigualdade, a massificação e a violência - e que, por sua vez, coloca algumas implicações no campo da educação escolar” (DE LIMA; HORN, 2019, p. 727).

O Brasil pratica uma cidadania historicamente incompleta e falha, "marcada por políticas de mandonismo, muito patrimonialismo, várias formas de racismo, sexismo, discriminação e violência” (SCHWARCZ, 2019, p. 24). Schwarcz explicita ainda que esses elementos, juntamente com o patriarcalismo, a desigualdade e a intolerância social estão: “[...] teimosamente presentes em nossa história pregressa e que encontram grande ressonância na atualidade.” (Idem, p. 26).

Ao passo que a crise social se acentua com o recrudescimento da crise econômica e sanitária advinda da pandemia de Covid-19, vê-se os impactos de uma série de medidas de austeridade adotadas pelo governo brasileiro desde 2015, que atinge diretamente a extensão dos direitos sociais conquistados com a Constituição de 1988, particularmente nas áreas de educação e saúde.

Dentre estas medidas, a Emenda Constitucional 95/2016 (EC 95) ou Emenda do Teto dos Gastos, em vigor desde 2017, reduziu as obrigações legais do estado brasileiro para com as políticas sociais ao estabelecer o congelamento do gasto público por 20 anos, acentuando os níveis de desigualdades e negligenciando os direitos sociais e econômicos básicos, particularmente da população em situação de pobreza e extrema pobreza.

Vale sublinhar ainda o impacto dessa medida para as mulheres negras brasileiras, visto que elas,

[...] são super-representadas entre os mais pobres e sub-representadas entre os mais ricos (ECLAC, 2017: 55, 231). Em 2011, quase 15\% da população negra brasileira encontravase entre os $10 \%$ mais pobres, enquanto apenas $7 \%$ dos brancos estavam nesse segmento. Além disso, quase $20 \%$ das mulheres negras encontravam-se entre os $10 \%$ mais pobres em contraste com apenas $5 \%$ de homens brancos. Portanto, as políticas tributárias regressivas do Brasil, que oneram mais os pobres, indiretamente discriminam as mulheres negras (INESC, 2014), enquanto beneficiam desproporcionalmente homens brancos ricos (INESC, 2017, p. 3). 
É óbvio que a redução dos direitos sociais amplia as desigualdades econômicas, de gênero e raça no país. Nestes termos, a Síntese de Indicadores Sociais do IBGE (2020) converge com as análises empreendidas ao apontar que

A desigualdade racial, histórica na estruturação da sociedade brasileira, é evidenciada na
análise da desigualdade de rendimentos. O rendimento domiciliar per capita médio da
população preta ou parda, ao longo do período compreendido entre 2012 e 2019 ,
permaneceu cerca de metade do observado para a população branca. Esse rendimento
foi, em 2019 , de R $\$ 91$ para a população preta e parda e $\$ 1948$ para a branca (Tabela
2.7). Embora a distribuição geral da população brasileira por cor ou raça tenha sido de
$42,7 \%$ para a população branca e $56,3 \%$ para a preta e parda, em 2019 , essa estava
sobrerepresentada entre os $10 \%$ com menores rendimentos, compondo $77 \%$ desse
grupo. No outro extremo, entre os $10 \%$ com maiores rendimentos, a população branca
era maioria $(70,6 \%$ [...] (IBGE, 2020 , p. 55 ).

A desigualdade de rendimentos entre as populações branca e preta ou parda advém, dentre outros fatores, da histórica segregação racial no mercado de trabalho. Convém ainda ressaltar que pessoas pretas ou pardos permanecem em sua maioria em atividades com rendimentos inferiores à média, enquanto pessoas brancas ocupam funções com rendimentos superiores à média. Nessa direção, os dados do IBGE (2020) retratam que:

O recorte por cor ou raça mostra que, dentre os ocupados, a proporção de brancos era
de $45,2 \%$ e a de pretos ou pardos, de $54,8 \%$. Todavia, a comparação por atividades
econômicas revela uma característica importante na segmentação das ocupações e a
persistência, ainda hoje, da segregação racial no mercado de trabalho. A presença dos
pretos ou pardos é mais acentuada nas atividades de Agropecuária $(62,7 \%)$, na
Construção $(65,2 \%$ ) e nos Serviços domésticos (66,6\%), atividades que possuíam
rendimentos inferiores à média em 2019 (Tabela 4). Já Informação, financeira e outras
atividades profissionais e Administração pública, educação, saúde e serviços sociais, cujos
rendimentos médios foram bastante superiores à média, são os agrupamentos de
atividades que contavam com a maior participação de pessoas ocupadas de cor ou raça
branca [...] (IBGE, 2020, p. 31).

É perceptível que os problemas estruturais de pobreza, racismo e segmentação do mercado de trabalho brasileiros corroboram para a ampliação das disparidades educacionais entre famílias de maior e menor renda, que residem na zona urbana ou rural, e em uma ou outra região do país. Portanto, significa dizer que os diferenciais de oportunidades educacionais, segundo as condições de renda e localização geográfica dos estudantes, dentre outros, são fatores determinantes para os processos de escolarização no Brasil.

E mais, que o acesso à escola das maiorias, das periferias, é condição necessária, mas não suficiente para contribuir com possibilidades concretas de mudanças na vida de parcela expressiva da população brasileira, na medida em que o processo de exclusão educacional não ocorre mais e principalmente na questão do acesso, mas também dentro da escola, particularmente quando vivenciamos uma pandemia como a de Covid-19, em que a população mundial é afetada por suas 
consequências sanitárias e econômicas, com intensidade maior entre a população pobre e vulnerável, pois nela figuram, dentre outros, aqueles com menor instrução e patrimônio, com empregos inseguros e ocupações com pouca qualificação.

As repercussões da pandemia de Covid-19 sobre a educação, o trabalho e as juventudes no Brasil

Cerca de 150 milhões de pessoas no mundo viverão em extrema pobreza em 2021 (BANCO MUNDIAL, 2020) devido à pandemia de Covid-19, à recessão, os conflitos e as mudanças climáticas. E essa crise planetária resultará na ampliação das desigualdades e na diminuição da mobilidade social, comprometendo seriamente a equidade educacional. A globalização do vírus escancara as desigualdades sociais e a recessão econômica, agravando o desemprego e o trabalho precário.

Em termos globais, o impacto da pandemia de Covid-19 exige respostas que envolvem a luta pelo acesso aos espaços de conhecimento vinculados ainda mais ao resgate da cidadania, em particular para a população pobre e em extrema pobreza.

As consequências da pandemia de Covid-19 sobre a educação no Brasil são imediatas, pois apesar dos avanços nas últimas décadas, o sistema educacional do país continua sustentando as bases da desigualdade social que determinam a história do país e não favorecendo o pleno acesso e as condições de equidade, limitando o fomento de melhores condições de vida da maioria da população. Schwartz (2019) contribui para que se compreenda essa realidade ao enfatizar que a

[...] Desigualdade não é uma contingência ou um acidente qualquer. Tampouco é uma decorrência "natural" e "imutável" de um processo que não nos diz respeito. Ao contrário, ela é consequência de nossas escolhas - sociais, educacionais, políticas, culturais e institucionais -, que têm resultado numa clara e recorrente concentração dos benefícios públicos para uma camada diminuta da população (SCHWARTZ, 2019, p. 150).

A negligência de diversas condições sociais interfere no processo de ensino-aprendizagem de crianças, adolescentes e jovens das escolas brasileiras. E, muitas vezes, ela é ocultada através da culpabilização desses sujeitos pela sua situação de fracasso escolar.

A escola brasileira oferta uma estrutura verticalizada e cumpre uma função seletiva e classificadora, demarcada pelas contradições sociais do sistema capitalista. À medida que esta escola não assegura as bases materiais concretas para cumprir com os objetivos da escolarização, ela se torna excludente e desigual. Em poucas palavras, os processos educativos influenciam e sofrem influência da realidade social brasileira e global.

Seguindo a mesma linha de raciocínio, Santos (2019) ressalta: 
Por isso, o modelo atual de escola e sua razão existencial, na conjuntura neoliberal, precisam ser compreendidos a partir de determinações pautadas nas exigências de um campo político voltado à formação para o consumo de bens materiais e imateriais que o hegemonize de forma cada vez mais robusta. Nesse campo, a democracia e a cidadania se consolidam pela restrita formalidade liberal (por meio da positivação legal), e não pela possibilidade de se pensá-las como empoderamento e emancipação simbólica - e, muitas vezes, física - das condições impostas pelo capital (SANTOS, 2019, p. 13).

Abramovay, Andrade e Esteves (2007) destacam, por conseguinte, que o protagonismo juvenil na área educacional tem direta relação com a cidadania, pois atua em prol do desenvolvimento de atividades que valorizam a participação e escuta dos jovens. Corroborando essas reflexões, Flach (2011, p. 298) diz que: “[...] sem a educação não pode haver cidadania. Também o pleno exercício da democracia encontrar-se-á entravado se esse direito social não for amplamente assegurado à população".

Direcionando o olhar sobre as juventudes e a pandemia de Covid-19 no Brasil, a pesquisa Juventudes e a pandemia do Coronavirus - $2^{a}$ edição (2021), coordenada pela Conjuve ${ }^{1}$, aponta importantes indicadores sobre os efeitos da pandemia na vida escolar e trabalho dos jovens brasileiros.

Realizada entre 22 de março e 16 de abril de 2021, através da aplicação de questionários para 68.114 jovens brasileiros, a pesquisa apresenta cinco blocos temáticos: perfil sociodemográfico dos participantes; saúde; educação; trabalho e renda; e vida pública. Este artigo irá priorizar alguns dados da pesquisa da Conjuve (2021) que tratam da escolarização, abandono escolar, ensino remoto e do ingresso precoce das juventudes no mercado de trabalho em tempos de isolamento social no Brasil.

O impacto da pandemia da Covid-19 na escolarização, vida profissional e saúde física/mental das juventudes segundo a pesquisa da Conjuve

A pandemia da Covid-19 impactou a escolarização da população em idade escolar de nosso país, visto que a maioria dos estudantes permaneceu sem aula por um longo período até que as instituições educacionais organizassem a oferta do ensino remoto. Por sua vez, a ausência de recursos tecnológicos nas residências da maioria dos estudantes favoreceu o aumento da exclusão educacional. A pesquisa realizada pela Conjuve com as juventudes brasileiras proporciona reflexões relevantes sobre este contexto.

A composição dos jovens participantes em termos geográficos foi assim delimitada na pesquisa: $10 \%$ da região Norte; $30 \%$ da região Nordeste; $8 \%$ da região Centro-Oeste; $39 \%$ da região

\footnotetext{
${ }^{1}$ A pesquisa foi realizada pela CONJUVE em parceria com a Fundação Roberto Marinho, a Rede Conhecimento Social, a Organização das Nações Unidas para a Educação, a Ciência e a Cultura (UNESCO), Em Movimento, Visão Mundial, Mapa Educação e Porvir.
} 
Sudeste e 13\% da região Sul. E a faixa etária da amostra foi compreendida por: $21 \%$ de jovens de 15 a 17 anos, $48 \%$ de jovens de 18 a 24 anos e 31\% de jovens de 25 a 29 anos.

O impacto da pandemia de Covid-19 na escolarização dos jovens é confirmado quando a pesquisa da Conjuve revela que 56\% dos jovens que não estavam estudando realizaram o trancamento ou cancelaram a matrícula após o início da pandemia, em março de 2020. Quando se analisa este dado considerando a faixa etária dos jovens, observa-se que o índice com maior abandono ocorreu entre os jovens de 15 a 17 anos (68\%), seguida pelos jovens de 18 a 24 anos (63\%) e em último aqueles da faixa etária de 25 a 29 anos (49\%).

Ressalta-se ainda que os dois principais motivos indicados pelos jovens por terem parado de estudar foram o financeiro $(21 \%)$ e a dificuldade de se organizar com o ensino remoto $(14 \%)$. Quando há um cruzamento deste dado com as faixas etárias das juventudes, percebe-se que os jovens de 20 a 25 anos (24\%) são os que mais pararam de estudar devido ao fator financeiro. E os jovens de 15 a 17 anos (20\%) são os que tiveram maiores dificuldades com o ensino remoto.

Os resultados da pesquisa revelam também que a pandemia tem favorecido o interesse dos jovens em abandonar a escola (43\%), e indicam que 4 a cada 10 participantes já pensaram em parar de estudar. Destaca-se, outrossim, que os jovens de 18 a 24 anos compõem o grupo com maior interesse em desistir dos estudos (49\%), seguidos dos jovens de 25 a 29 anos (47\%) e dos jovens de 15 a 17 anos (32\%).

Se o fenômeno do abandono escolar entre adolescentes e jovens brasileiros já se fazia presente antes da pandemia do Covid-19, era previsível que ele sofreria um aumento ao longo do período pandêmico. E, certamente, um dos principais motivos para o não retorno à escola tem sido a necessidade de os jovens trabalharem para complementar a renda familiar, em especial os jovens pertencentes às famílias em situação vulnerável.

Importa considerar ainda que a precarização do mundo do trabalho, cada vez mais incerto e voraz no consumo da força laboral, com exacerbação das condições de exploração, conduz a escola a perder a sua eficácia, de maneira a tornar-se menos atrativa para os jovens, na medida em que não atende com efetividade às perspectivas juvenis.

A pesquisa da Conjuve revela também as consequências da pandemia sobre o número de jovens que ingressaram pela primeira vez no mercado de trabalho, apontando que

Os efeitos da pandemia sobre a vida profissional das juventudes têm marcado não apenas a renda e as formas de trabalho, mas também o ingresso no mercado de trabalho: 4 a cada 10 jovens que estão trabalhando estão em seus primeiros trabalhos, subindo para 5 a cada 10 entre aqueles com 18 a 24 anos (CONJUVE, 2021, p. 40). 
E também que

Entre jovens consultados que não estão trabalhando, 3 a cada 10 não estão estudando. A maior parte deles estão procurando trabalho, sendo que 4 a cada 10 estão nessa busca pela primeira vez. A dependência financeira é a realidade da grande maioria deles, mas $7 \%$ contribuem para sustentar o seu domicílio total ou parcialmente (CONJUVE, 2021, p. 42).

Milhões de trabalhadores perderam seus empregos ao longo da pandemia e a escolarização não é prioridade diante de demandas mais imediatas das famílias brasileiras. A escola perde espaço no mundo dos jovens, que buscam uma inserção no mercado de trabalho formal ou não formal, mesmo diante de uma realidade marcada pelo desemprego. Portanto, o isolamento social aliado ao fator econômico favorece o abandono escolar.

Antunes (2020) é preciso em seu pensamento ao inferir que a classe trabalhadora se encontra sob um intenso enfrentamento diante de uma crise pandêmica, considerando que

[...] é preciso que haja isolamento social e quarentena para se evitar o contágio pelo coronavírus. Sem isso, a classe trabalhadora será cada vez mais contaminada, adoecendo e perecendo em maior quantidade. Mas como ficarão em isolamento social os/as desempregados/as, os/as informais, os trabalhadores/as intermitentes, os/as uberizados/as, os/as subutilizado/as, os/as terceirizado/as isto é, aqueles que não têm direitos sociais e que recebem salários somente quando executam algum trabalho? $\mathrm{E}$ quanto ao pequeno "empreendedor" [...] que em meio à pandemia não tem o que vender (pois não há consumidores), nem renda, nem previdência, nem convénio de saúde? Como será possível driblar o trabalho dito flexível, digital, "moderno", que tenderá a se intensificar enormemente se o capital pandêmico continuar a comandar o mundo segundo seus interesses? (ANTUNES, 2020, p. 17).

A pandemia de Covid-19 modificou totalmente o dia a dia da população, principalmente em termos de privação do convívio social, consequência do medo de contágio da doença, que, aliado à ansiedade, favorecem a insônia e afetam a alimentação e as emoções, impactando diretamente o humor e a concentração das juventudes.

O segundo principal motivo dos jovens pesquisados terem parado de estudar, segundo a pesquisa da Conjuve (2021) foi a dificuldade de se organizar com o ensino remoto, o que pode ter relação com a ansiedade e a falta de acesso a equipamentos digitais e uma conexão de qualidade, até com a incapacidade de prover a própria subsistência ou de conciliar os estudos com trabalhos precários e domésticos, passando por prejuízos, sofrimentos e perdas, que afetam significativamente sua saúde física e mental: perda de trabalho e renda, perda de direitos, perda de parentes e amigos levados pela doença, entre outros.

Esse quadro de estresse social se configura como fator de risco a saúde mental, ao gerar sofrimento psíquico dos estudantes. Portanto, os desafios enfrentados pela comunidade escolar em 
tempos de pandemia e de ensino remoto são diversos, particularmente os que são vivenciados pelos professores e alunos. E sobre o tema, Amaral e Polydoro depreendem que

\begin{abstract}
Dentre outros desafios vividos por professores e estudantes, Crawford et al. (2020) enumeram a [...] falta de domínio de recursos e competências digitais para projetar ou aprender no ensino digital. A garantia de uma infraestrutura de rede confiável é um dos elementos principais para o ERE, a fim de garantir participação nos momentos síncronos, usar recursos em tempo real, assistir a vídeos, baixar materiais, fazer upload, trabalhar com colegas em produções colaborativas (HUANG et al., 2020). Além disso, alguns cuidados também deveriam ser considerados para que os estudantes pudessem gerenciar de forma mais autônoma sua aprendizagem, sem contato presencial com colegas e equipe acadêmica (SANDARS et al., 2020). Em acréscimo, Meyer (2014) alerta que o estudante pode não dispor de tempo suficiente para as atividades, não ter experiência prévia com a aprendizagem online e não saber como agir, ter dificuldade em autorregular seu próprio comportamento, ser menos disposto a metodologia ativa ou preferir abordagens face a face (AMARAL; POLYDORO, 2020, p. 55/56).
\end{abstract}

Em resumo, o contexto pandêmico vivenciado em nosso país ampliou as desigualdades sociais e favoreceu o abandono escolar, que se torna um dos maiores desafios educacionais, particularmente quando o olhar é direcionado para as juventudes brasileiras.

É primordial a implementação de políticas públicas combinadas, que possibilitem um contexto em que crianças, adolescentes e jovens possam retornar à escola com condições socioeconômicas mínimas para a sua existência, contando com professores dispostos a proporcionar a construção do conhecimento e uma equipe multiprofissional escolar que identifique e atue diante de fatores sociais, econômicos e culturais que impactam as vidas dos alunos.

\title{
Considerações Finais
}

O presente artigo foi idealizado com o intuito de contribuir com o debate sobre a pandemia de Covid-19, as desigualdades sociais e as condições desfavoráveis de permanência da população em idade escolar na educação básica no Brasil, partindo do entendimento que a educação é um direito e não um privilégio de determinada classe social.

Todavia, permanecemos com o desafio histórico de garantir o acesso da população à escola e ofertar um ensino crítico e de qualidade para todos, posto que a política de educação é arena de disputas e interesses em detrimento da construção de uma cidadania participativa que fomente a superação das desigualdades sociais. Portanto, o sistema educacional configura-se como espaço de adequação dos sujeitos ao modo de produção capitalista e de reprodução da ordem social vigente.

Esta realidade amplia as dificuldades enfrentadas pelos estudantes, pois envolvem diversas dimensões, desde as questões pedagógicas até as estruturais. A ausência de uma política pública que conheça e priorize as demandas de seu público, o distanciamento entre o que está nos documentos oficiais e o que ocorre na prática diária da escola e da sala de aula, a fragilidade da 
formação continuada dos professores para atuarem no ensino remoto ou híbrido representam alguns dos atuais desafios enfrentados pela sociedade brasileira.

Mudar essa realidade implica no entendimento sobre o papel da escola para o desenvolvimento psicossocial das crianças e jovens através da escuta qualificada, compreendendo os desafios que esse público enfrenta na sociedade atual. Os profissionais que atuam no espaço escolar precisam refletir sobre como podem, mediante uma educação crítica e reflexiva, contribuir para que seu público encontre respostas para os desafios do meio social em que vivem.

A sociedade brasileira tem ainda o desafio de favorecer uma aprendizagem de qualidade para todos, independente de classe social, raça, religião ou gênero. Para tanto, o processo de ensinoaprendizagem deve incluir o desenvolvimento de todas as dimensões dos sujeitos sociais (humana, social e política). Dessa forma, é possível apreender o quão essencial se torna constituir espaços para o diálogo em que os jovens possam compartilhar suas vivências, conhecimentos, experiências, assim como ponderar sobre o que precisam e o que podem fazer individual e coletivamente enquanto protagonistas de suas escolhas.

\section{Referências}

ABRAMOVAY, Miriam; ANDRADE, Eliane Ribeiro; ESTEVES, Luiz Carlos Gil (Org.). Jwventudes: outros olhares sobre a diversidade. Brasília, DF: MEC, 2007.

AMARAL, Eliana; POLYDORO, Soely. Os desafios da mudança para o ensino remoto emergencial na graduação na Unicamp - Brasil. Linha Mestra, n. 41A, p 52-62, HTTPS:/ /DOI.ORG/10.34112/1980-9026A2020N41AP52-62, set. 2020. Acesso em: 10 de jul. de 2021.

ANTUNES, Ricardo. Coronavirus: o trabalho sob fogo cruzado. São Paulo: Boitempo, 2020.

BANCO MUNDIAL. La pobreza y la prosperidad compartida 2020: Un cambio de suerte. Relatório 2020. Grupo Banco Mundial. Disponível em:

https://openknowledge.worldbank.org/bitstream/handle/10986/34496/211602ovSP.pdf?seque nce $=21 \&$ is Allowed $=y$ Acesso em: 01 de fev. de 2021 .

BRASIL. Emenda Constitucional n 95. Altera o Ato das Disposições Constitucionais Transitórias, para instituir o Novo Regime Fiscal, e dá outras providências. Presidência da República. Brasilia,15 de dezembro de 2016.

CARRANO, Paulo. A escola pública diante do desafio de educar em relações de liberdade e convivência democrática. In: KRAWCZYK, Nora (org.). Escola pública: tempos difíceis, mas não impossíveis. FE/UNICAMP, Campinas, SP; Uberlândia, MG: Navegando, p. 74-96, 2018.

CHARLOT, Bernard. Da relação com o saber às práticas educativas. São Paulo: Cortez, 2013. 
CONJUVE. Juventudes e a Pandemia do Coronavírus - 2a edição (2021). Relatório Nacional.

CONSELHO NACIONAL DE JUVENTUDE (CONJUVE), Brasília, 2021.

DE LIMA, Luciana Vieira; HORN, Geraldo Balduino. Educação e justiça social à luz da teoria crítica da sociedade. Revista Espaço Pedagógico, v. 26, n. 3, p. 719-737, 4 set. 2019.

FLACH, Simone de Fátima. Direito à educação e obrigatoriedade escolar no Brasil: entre a previsão legal e a realidade. Revista HISTEDBR On-line, Campinas, SP, v. 11, n. 43, p. 285-303, 2012. DOI: $10.20396 /$ rho.v11i43.8639943.

IBGE. Sintese de indicadores sociais: uma análise das condições de vida da população brasileira: 2020 / IBGE, Coordenação de População e Indicadores Sociais. Rio de Janeiro: IBGE, 2020. 148 p. Disponível em: https://biblioteca.ibge.gov.br/visualizacao/livros/liv101760.pdf Acesso em: 01 de fev. de 2021.

INESC. Monitoramento dos Direitos Humanos em Tempos de Austeridade no Brasil. Distrito Federal. Maio de 2018. Disponível em: http://www.rebrip.org.br/system/uploads/publication/f9cf836b7a062ccd1d3f772cf950a2e7/file /inesc-dh.pdf Acesso em: 01 de fev. de 2021.

LEÓN, Jaime Ernesto Winter Hughes. Mudanças sociais no Brasil neodesenvolvimentista a partir de uma análise da relação entre Estado, economia e sociedade. In: XVII SEMINÁRIO SOBRE A ECONOMIA MINEIRA. Diamantina, 2016, Minas Gerais [recurso eletrônico]: Anais... Belo Horizonte: UFMG/Cedeplar, 2016. Vol.1 - Págs.: 1446-1464.

LIMA, Licínio C.; AFONSO, Almerindo Janela; GOMES, Carlos Alberto. Posfácio: possibilidades e limites de políticas e práticas socioeducativas de inclusão. In: ANTUNES, Fátima (Org.). Remar contra as desigualdades em educação: práticas, vozes, percursos. Edições Húmus, 2019.

MACENO, Eugênio Talvanes. A Impossibilidade da Universalização da Educação. São Paulo: Instituto Lukács, 2019.

SANTOS, Émina. A educação como direito social e a escola como espaço protetivo de direitos: uma análise à luz da legislação educacional brasileira. Educação e Pesquisa, São Paulo, vol. 45, e184961, 2019.

SCHWARCZ, Lilia Moritz. Sobre o Autoritarismo Brasileiro. São Paulo, Companhia das Letras, 2019.

TELLES, Vera da Silva. Direitos Sociais: afinal do que se trata? Belo Horizonte: Ed. UFMG, 1999.

VALE, Erlênia Sobral do; SOUZA, Nathalia Martins de. A educação, a universidade e o trabalho docente no quadro da reprodução social neoliberal. In: ANDRADE, Francisca Rejane Bezerra (Org.) Serviço Social: uma profissão, distintos olhares. Fortaleza: Eduece, p. 37-66, 2017. 